\title{
Using Facebook to support learning and exam preparation in a final year undergraduate pharmacy clinical therapeutics module
}

DOI:

10.1016/j.cptl.2015.08.010

\section{Document Version}

Accepted author manuscript

Link to publication record in Manchester Research Explorer

Citation for published version (APA):

Mawdsley, A., \& Schafheutle, E. (2015). Using Facebook to support learning and exam preparation in a final year undergraduate pharmacy clinical therapeutics module. Currents in Pharmacy Teaching and Learning, 7(6), 869875. https://doi.org/10.1016/j.cptl.2015.08.010

Published in:

Currents in Pharmacy Teaching and Learning

\section{Citing this paper}

Please note that where the full-text provided on Manchester Research Explorer is the Author Accepted Manuscript or Proof version this may differ from the final Published version. If citing, it is advised that you check and use the publisher's definitive version.

\section{General rights}

Copyright and moral rights for the publications made accessible in the Research Explorer are retained by the authors and/or other copyright owners and it is a condition of accessing publications that users recognise and abide by the legal requirements associated with these rights.

\section{Takedown policy}

If you believe that this document breaches copyright please refer to the University of Manchester's Takedown Procedures [http://man.ac.uk/04Y6Bo] or contact uml.scholarlycommunications@manchester.ac.uk providing relevant details, so we can investigate your claim.

\section{OPEN ACCESS}




\title{
Using Facebook to support learning and exam preparation in a final-year undergraduate pharmacy clinical therapeutics module
}

\author{
Andrew Mawdsley, MPharm, PGDipClinPharm, PGCertClinEd, FHEA, MRPharmS, \\ MFRPSII", Ellen I. Schafheutle, MSc, Mres, PhD, FFRPS, MRPharmS \\ Manchester Pharmacy School, The University of Manchester, Manchester, UK
}

\begin{abstract}
Background: A Facebook page was created to engage United Kingdom (UK) Master of Pharmacy (MPharm) students in learning and exam preparation.

Aims: The aim of this study was to gauge student opinion on this method of teaching using social media.

Method: Facebook usage data were analyzed using simple frequencies. A survey was administered to all final-year MPharm students $(n=171)$.

Results: The page received 142 "likes" indicating active followers. Total "engagement" peaked at 369 page clicks; peak weekly "reach" totaled 2391 page views; and peak "hit" rate was 9234 interactions. In all, 48 students (28\%) completed the survey. Overall, 69\% found the page very useful, 78\% strongly agreed that it benefitted exam performance, $91 \%$ valued module leader support, and $86 \%$ valued practice multiple-choice questions (MCQs). Peer support was valued highly (71\%). Five themes emerged from open comments; revision support, module leader support and communication, assessment and feedback, peer support, and negative feelings towards social media.

Conclusion: This evaluation demonstrates that students engage in social media learning, particularly if it is perceived as having a direct benefit to assessment.

(C) 2015 Elsevier Inc. All rights reserved.
\end{abstract}

Keywords: Assessment; Facebook; Social media

\section{Introduction}

The United Kingdom (UK) has the second highest proportion of social networkers in the European Union (EU), with $90 \%$ of social network users in the 16-24 age range. ${ }^{1}$ Facebook, with 1.44 billion active users, ${ }^{2}$ is the most popular social networking site in the world. ${ }^{3}$ Because of this, social media platforms (particularly Facebook) are

\footnotetext{
* Corresponding author: Andrew Mawdsley, MPharm, PGDipClinPharm, PGCertClinEd, FHEA, MRPharmS, MFRPSII, Manchester Pharmacy School, The University of Manchester, Stopford Building, Oxford Road, Manchester M13 9PT, UK.

E-mail: Andrew.Mawdsley@manchester.ac.uk
}

increasingly utilized for educational purposes, ${ }^{4}$ and several studies have investigated this. ${ }^{3-6}$

Health care and the health professions are also embracing this digital age. ${ }^{7}$ This is seen within pharmacy, where pharmacists employ social media for professional representative activities, ${ }^{6,8}$ and undergraduates are organically utilizing social media to support their learning in synchronous casual peer groups. ${ }^{9}$ However, social media are not universally welcomed for professional students, and there are concerns around how, and for what purpose, these media are being used by this population. ${ }^{10,11}$ Indeed, this activity is not always productive for learning, particularly if unmoderated. $^{10,12}$ The value of using social media to positively support student engagement and course-based 
discussion, ${ }^{6,13-16}$ balanced with potential challenges with e-professionalism, are increasingly highlighted in the literature. ${ }^{6,11,17-22}$

Facebook is commonly used by students for informal learning and collaboration, but offers the ability to enhance student-teacher rapport. ${ }^{6,12}$ Indeed, the pedagogical paradigm of socio-constructivism through situated learning, in particular communities of practice, has proven applications to such e-learning initiatives. ${ }^{23}$ Learners are positive about the educational uses of Facebook ${ }^{\circledR}$ if there is perceived usefulness $^{4}$ and thus mutual engagement, joint enterprise, and shared repertoire. ${ }^{24}$

Blackboard ${ }^{\circledR}$ and related asynchronous virtual learning environments (VLEs) have restricted functionality, little uptake, and students are widely turning to social media platforms to communicate about studies beyond traditional institutional technologies. ${ }^{12,25}$ Modern students are digital natives, ${ }^{26}$ so it is important for teachers to consider the formalization of innovative and familiar technologies into curriculum design to capitalize on learners' interest and motivation for this genre of community learning. ${ }^{27}$ Considering that learners are naturally turning to social media to support their learning, it is worth exploring if, and how, learners can be supported in their preparation for summative assessment using Facebook as a preparatory platform.

The aim of this study was to design a Facebook page to support pharmacy students' social online learning and exam preparation, and to gauge student opinion on this method of support through social media. It was expected that students would adopt an active, self-directed approach to exam preparation if supported and empowered to take greater ownership of the course material. This intervention and evaluation will thus consider an alternative platform to a VLE (i.e., Facebook) in engaging students in learning and assessment.

\section{Material and methods}

In the UK, in order to qualify as a pharmacist, students undertake a four-year undergraduate Master of Pharmacy (MPharm) degree, followed by a one-year period of preregistration training in practice. The course is mainly university taught, with limited practice exposure and placements. Whilst pharmacy practice teaching is increasingly introduced early, and spirals up through the four years, clinical teaching and application tends to be located in the later years. ${ }^{28}$

"Disease Management 2" was a ten-credit clinical therapeutics module, situated in semester 1 of the fourth (and final) year of the MPharm course at Manchester Pharmacy School, UK. The module consisted of 22 lectures and six hospital placement visits covering the pathology and therapeutics of endocrine, respiratory, immune, nutritional, and dermatological systems. ${ }^{29}$ Assessment was via written examination (80\%) and a clinical case report (20\%). Being a final-year module, the stakes are typically high and the module is deemed particularly demanding. The module utilizes the University VLE, Blackboard, for file sharing, timetabling, assessment submission, as well as social aspects such as discussion forums. A Blackboard discussion board was open throughout the module until after the examination period. This was a forum for student discussion about the module and as a point for contact and support from the module leader. However, in the past, this facility has not been well used by students or teaching staff; discussion boards are not readily accessible across wireless technologies such as tablet computers and smartphones. These boards do not usually provide notifications that content has been uploaded and so require learners to impetuously check for updates. Facebook could potentially bridge these technical limitations.

An "Exam Preparation" Facebook page was created by the module leader (and lead author) and was launched in week 12 of semester 1 , the final week of the formal teaching. The page was created to engage students in exam preparation and in particular, module content, to complement formal teaching beyond core module hours. The page engaged students in assessment preparation through online discussion of sample questions, lecture content, directed reading, web resources, and frequently asked questions. This was done through a variety of methods such as posting sample questions to facilitate discussion and problemsolving, uploading, or linking to further online resources (including YouTube videos, images, and documents), and visible open posing of shared questions exploring knowledge gaps or misunderstandings faced through lectures and self-study. The page operated for six and a half weeks (throughout the Christmas holiday period), until one day after the final written examination. The moderator decided to make this an open page (open to all Facebook users to access as opposed to a page closed to the wider Facebook community). In doing so, learners were not obligated to become "friends" with the page ("friends" being active followers of the page with mutually relaxed page privacy settings unless adjusted by the user). Becoming "friends" with the page allows the moderator access to individual personal profiles. By using an open page, learners had the choice whether they joined the page (i.e., received updates about the page in their personal profile feeds) or not (to maintain personal privacy). In this way, everybody could engage in page content, but make choices about personal privacy and whether to receive page notifications within their page profile feed. Considering the literature noting concerns students have with online privacy, ${ }^{25,30}$ the moderator felt this approach would increase student engagement with the page. As an aim of the page was content consolidation and revision in preparation for assessment, the page was open only after formal teaching had finished, and was not used as a formal teaching tool. Page creation is a simple and quick task, developed in week 11 of semester 1. A link to the Royal Pharmaceutical Society guide to social media ${ }^{8}$ was uploaded to the page for users to consider digital professionalism. 
Drawing on the work of Salmon, ${ }^{31}$ and the five-stage model of e-moderation, the module leader was the page moderator, actively posting on the page at least five times per day (questions, discussion points, web links, videos, etc.) to encourage socialization, participation, and development. The moderator prompted, initiated, and concluded the resolution of learning needs and knowledge gaps. The page was available to be checked for notifications via mobile devices and thus became 24/7 in nature.

Facebook allows for the export of usage data to be downloaded in Excel for descriptive analysis using simple frequencies. (This is automatically collected and can be generated at any time. Facebook also provide the moderator snapshot data by e-mail and through the page itself.) Data for page "likes" (active page followers), "engagement" (any click or story created on the page), "reach" (number of people who have seen any content associated with the page), and "impressions" (the number of times that any content associated with the page was seen) were recorded.

To gather students' views on Facebook as a learning tool, and specifically the value of this page in supporting learning and exam preparation, a questionnaire consisting of eight closed questions and one open question was developed. Closed questions used 5-point Likert scales (for agreement and usefulness) and a 3-point scale (very useful to not useful). One question asked respondents whether they had used the Facebook page. Five questions explored students' perceptions of the page; if they felt it benefited exam performance, the value of teacher support, and page content that was useful for learning. Students were asked if they felt supported by their peers, and if they would welcome this type of learning tool in the future. One question listed nine specific activities on the page and asked if respondents found each useful for their learning. Finally, an open question offered respondents the opportunity to feedback both negative and positive comments about the page in general. Open comments were analyzed for key emergent themes using a comparative method, ${ }^{32}$ to identify personal perceptions of learning through this page.

The questionnaire was piloted by two members of teaching staff and minor changes were made. It was created using Select Survey, and administered via the University year group e-mail distribution list and Facebook to all fourth-year students $(n=171)$ enrolled in the module (including students that did not use the Facebook page). The questionnaire was open for all respondents to answer each question, regardless of whether they used the page or not. The questionnaire opened one day after the summative assessment and was open for a four-week period, with reminders issued via Facebook and e-mail throughout the duration of the collection period. Respondents could access the survey only once.

This study is considered service evaluation, to inform and enhance teaching; therefore formal ethics committee approval was not required. However, the principles of good research design and governance were followed throughout the project.

\section{Results}

The page received 142 "likes" over the lifetime of the page. All these "likes" were received from students enrolled on the module, and not the wider Facebook community (since students needed to use University identification to log in to the survey). Page use increased as the exam date drew closer. Total daily "engagement" peaked the day before the written examination, with 369 page clicks and/or stories created. The peak weekly "reach" (the number of page content views) was during the week of the exam and totaled 2391 views. The page had a high viral reach (people seeing page content shared by a Friend); the highest cumulated on the week of the exam with 2222 people, which indicated that the page was actively and organically shared. The peak number of page "impressions"-or "hits"-was 9234 on the day before the exam; the peak cumulative impressions totaled 28,606 during the exam week. Since this page was open to the wider Facebook community, "impressions" and viral "reach" are not specific to the course learners; however, "likes" and "engagement" are stronger indicators for students' interactions with the page. These data are reported separately in the Facebook usage data so that moderators can interpret the page use by audience.

In all, $48(28 \%)$ fourth-year students completed the questionnaire. The low response rate can be attributed to the fact that the module had concluded and the questionnaire was administered in semester 2. It must be acknowledged that the majority of users did not complete the questionnaire; this is discussed as a limitation below. Table 1 provides details on how students perceived the page. Overall, $69 \%$ of respondents found the page very useful in preparing them for the examination, with $78 \%$ of students agreeing that it benefitted their exam performance. The vast majority (92\%) agreed that using social media was beneficial to their learning. Overall, 79\% agreed that the Facebook page gave them wider appreciation of the topic content and 96\% would welcome the use of social media to support their studies in the future.

Students were given a list of nine activities on the Facebook page and asked to rate how useful they found each activity for their learning (Table 2). Module leader contact/support $(90 \%)$, sample multiple-choice questions (MCQs) (96\%), sample short-answer questions (85\%), student questions with answers from the module leader $(89 \%)$, explanatory diagrams and pictures $(83 \%)$, and peer support $(80 \%)$ were perceived as particularly useful. On the other hand, Twitter retweets (9\%), YouTube videos (19\%), and web links to documents (25\%) were viewed as less useful.

In all, 26 respondents wrote comments in response to a question asking "please write any comments (positive 
Table 1

Perceived usefulness and benefit of the Facebook page

\begin{tabular}{|c|c|c|c|c|c|c|}
\hline Question & Strongly agree & Agree & Neutral & Disagree & Strongly disagree & Total \\
\hline $\begin{array}{l}\text { I would welcome the use of social media to support my } \\
\text { studies in the future }\end{array}$ & $36(75 \%)$ & $11(23 \%)$ & 0 & 0 & $1(2 \%)$ & 48 \\
\hline Using online social media is beneficial to my learning & $29(58 \%)$ & $17(34 \%)$ & $3(6 \%)$ & 0 & $1(2 \%)^{\mathrm{a}}$ & 50 \\
\hline $\begin{array}{l}\text { The Facebook page gave me wider appreciation of the topic } \\
\text { content }\end{array}$ & $20(42 \%)$ & $18(37 \%)$ & $9(19 \%)$ & $1(2 \%)$ & 0 & 48 \\
\hline The Facebook page benefitted my exam performance & $19(40 \%)$ & $18(38 \%)$ & $10(21 \%)$ & $2(4 \%)$ & 0 & 49 \\
\hline
\end{tabular}

$\%$ Are reported as valid \%, i.e., excluding missing data $(n=48-50)$.

${ }^{\mathrm{a}}$ One respondent did not use the page.

and/or negative) that you have about the Facebook page". Of them, 22 related to positive views on the benefits of the page and four were more negative. Comments could be grouped into five themes: revision support, module leader support and communication, assessment and feedback, peer support, and negative feelings. These themes, supported by illustrative quotes, are detailed in the Figure.

Open comments related to the perceived benefit of the page to the students' revision support; most were very positive and illustrated how the Facebook page acted as a valuable revision support tool that helped learners to identify learning needs and test understanding. Being an innovate tool within the wider program, students appreciated a novel approach to revision support.

The second theme provided further insight into what learners found particularly valuable in terms of the support and communication provided by the module leader. Learners mainly appreciated the ease of contacting the module leader, the speed with which they received responses, and the motivating nature of the posts and encouragement to learn. Association between teacher and student was seen as a strong motivator for using the page, highlighted by the following quote "it was really nice to know the module leader had our best interests at heart and really cared about helping us ... no other lecturer has done that throughout the pharmacy degree and it was appreciated by a hell of a lot of people” (ID 12). Affinity and collaboration with the module leader was seen as engaging, valuable, and supportive.

A third theme related to assessment and feedback. Many comments focused on the different types of feedback the module leader provided (written responses, post likes, and pictures); teacher-led and peer-led resolution of problems and decision making (teacher and learners providing written feedback to students who answered questions on the page). The benefit of seeing questions and worked answers to problems, and the help and encouragement provided to support learners to solve problems themselves, and with peers, were commented on.

The fourth theme related to peer support. Learners valued the opportunity to share responses and learning, and they felt comfortable in asking questions of each other. Indeed, there was encouragement for widening this way of sharing and learning.

The fifth theme that emerged was negative feelings towards social media. Learners commented that some peers did not use social media and may therefore be excluded from this learning resource. Learners also raised a number of concerns about privacy and personal life, which highlights the reach that social media can have into students' personal life, and how this may cause revision anxiety.

In comparison, the Blackboard discussion board received zero posts over the entire semester, even though the module leader did post discussion points.

Table 2

Considering the activity on the page, which of the following did you find useful to your learning?

\begin{tabular}{|c|c|c|c|c|c|c|}
\hline Activity & Very useful & Useful & Neutral & Useless & Very useless & Total \\
\hline Module leader support and contact & $44(90 \%)$ & $4(8 \%)$ & 0 & 0 & $1(2 \%)$ & 49 \\
\hline Sample MCQs & $42(86 \%)$ & $5(10 \%)$ & $1(2 \%)$ & $1(2 \%)$ & 0 & 49 \\
\hline Student questions with answers from the module leader & $34(69 \%)$ & $10(20 \%)$ & $3(6 \%)$ & $2(4 \%)$ & 0 & 49 \\
\hline Sample short-answer questions & $32(65 \%)$ & $10(20 \%)$ & $5(10 \%)$ & $1(2 \%)$ & 0 & 49 \\
\hline Explanatory diagrams and pictures & $25(53 \%)$ & $14(30 \%)$ & $5(11 \%)$ & $3(6 \%)$ & 0 & 47 \\
\hline Peer support and contact & $19(39 \%)$ & $20(41 \%)$ & $8(16 \%)$ & $1(2 \%)$ & $1(2 \%)$ & 49 \\
\hline Web links to documents & $12(25 \%)$ & $19(40 \%)$ & $10(21 \%)$ & $6(13 \%)$ & $1(2 \%)$ & 48 \\
\hline YouTube videos & $9(19 \%)$ & $16(33 \%)$ & $16(33 \%)$ & $6(13 \%)$ & $1(2 \%)$ & 48 \\
\hline Twitter retweets & $4(9 \%)$ & $8(17 \%)$ & $22(47 \%)$ & $10(21 \%)$ & $3(6 \%)$ & 47 \\
\hline
\end{tabular}

$\%$ Are reported as valid \%, i.e., excluding missing data $(n=47-49)$; MCQ, multiple-choice question. 


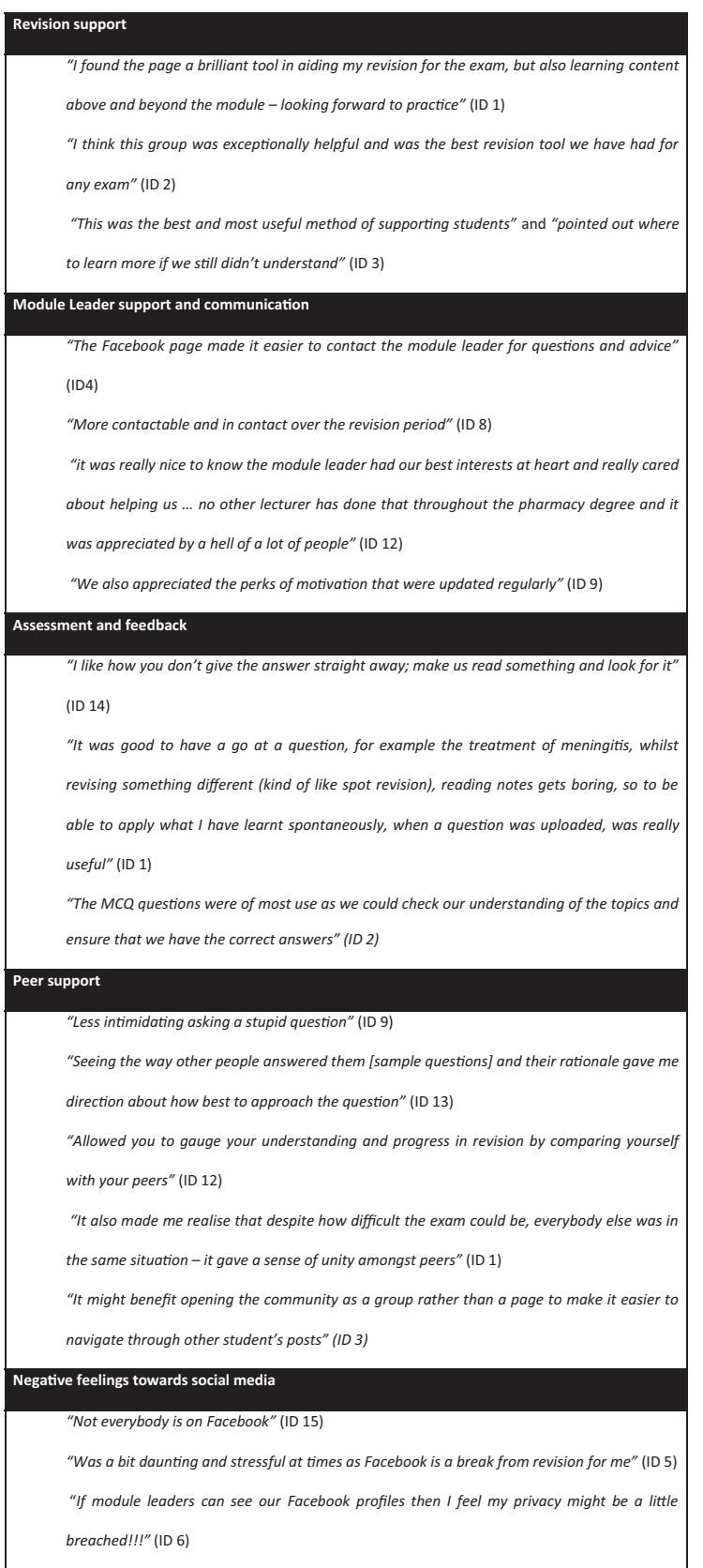

Fig. Open comments in response to the question "please write any comments (positive and/or negative) that you have about the Facebook page."

\section{Discussion}

Students widely use social media to communicate about their studies and learning. ${ }^{11,12}$ This is the first study which evaluated pharmacy student perceptions of a Facebook page set up to support learning and exam preparation, as part of an existing year four MPharm clinical module. It supports the literature demonstrating that students are positive about the use of Facebook in education, ${ }^{4}$ and demonstrates that pharmacy students engage in virtual social learning if it is perceived as having a direct benefit to assessment. Nevertheless, some also recognized the relevance to practice beyond assessment. Students will willingly engage in social learning if the process has an outcome, is investible, and the stakes are sufficiently high. ${ }^{27}$ This echoes previous work on student investment into social media groups that have mutual interests and knowledge. 4,33,34 $^{\text {. }}$

Despite many benefits to students' learning, this study also echoes the results of previous research, in particular concerns over personal privacy and the awkward contention between private and professional life. ${ }^{5,11,30,35}$ This will require further exploration, to ensure that social media can be incorporated into student learning in an engaging and trusted online environment. Respondents in this study highlight a contention between personal and private lives; social media infiltrating personal space can be "stressful." Considering a media platform that allows users to have multiple, separated accounts, such as Twitter, may help learners separate work from study.

Whilst peer support was considered valuable by students, the role of the module leader/page moderator was particularly appreciated, thus demonstrating the enhanced student-teacher relationship when a moderator situates and constructs the learning journey. This mirrors previous work that links social influence and social presence ${ }^{36}$ when engaging in collaborative learning and the impetus to involve oneself with a shared interest group online ${ }^{12,27}$; especially when the instructor is socially present and perceived as caring, people invested in something. ${ }^{12}$ This assumes the perspective of formative self-regulation through dialog and feedback when learning socially in an engaging and equitable environment. ${ }^{23}$ Exploring the digital relationships between teacher and learners would be an interesting area for future research.

Part of the reason for the success of this page (seen through page "likes" and "engagement") may indeed be due to the commitment of the moderator in creating an active, humored, and timely page. Engaging students in this way created a 24/7 means of communication. This should not be underestimated as a significant undertaking of time and capacity, and the impact of social media on teacher and facilitator time needs consideration. Creating a Facebook page is a simple task; the technology is useable and intuitive. However, in creating a forum that is not bound by time and place, the moderator constructs an on-demand platform that requires commitment of presence to maintain and direct interaction. Although expected by this page moderator, this would require consideration for other academics and programmes, and potentially the inclusion of ground rules and shared expectations. Although Blackboard can be used for discussion, the technology is less accessible. Facebook allows for passive involvement (content and material is pushed automatically into a followers page feed), whereas a VLE 
requires participants to actively seek out discussion. Active and enthusiastic moderation of a VLE discussion board may yield similar successes with student engagement. However, the technology itself may limit the breadth of activity (and analytics) that can be achieved. VLEs and Facebook are not comparable since one is social media and the other functions as a repository, and environment for structured, institutional learning. Although this communication was not intended as a technological comparison, it raises an interesting point for further research; does online social presence, through meaningful personal interaction, require participants to sacrifice a degree of privacy in order to create functional online learning groups? Without presence and relationship forming, social media may not function as a tool for social learning if participants do not allow for a degree of personal discretion. Although a VLE can be used for discussion (and has the potential to achieve as much interaction as a Facebook page), it is impersonal by nature. Would a VLE (or other social media platform) achieve as much peer and teacher contact if the community interrelation is better supported and encouraged by a moderator?

E-professionalism was not a main consideration when creating this online learning space and no issues with professionalism occurred. Personal privacy is a concern for certain learners when using personal profiles to access educational material that is moderated by a teacher. This issue of power relations, and access to private information, requires further research to fully understand the learner perspective and how this may limit using social media educationally. In this study, the majority of learners valued teacher input on a social level; however, this is a small-scale evaluation and does not account for opinions from learners who did not participate in the questionnaire. This study raises questions around access to social media, particularly feelings of exclusion and fairness. Some respondents felt excluded from this experience because they did not have a Facebook account. In this instance, the module leader uploaded a document to Blackboard that included all the Facebook page content to negate feelings of inequitable access to support prior to the examination. This is not sustainable or legitimate for academics who are committing to social media in teaching with an emphasis on learner participation. Educators should consider navigating issues relating to access prior to using social media. This example highlights a voluntary page that was not a formal requirement of the module. Education that mandates the use of social media accounts requires further consideration.

Staff/student rapport may be a reason why Twitter links, video, and links to additional documents were less appreciated by the learners; these are detached and impersonal resources lacking dialog, commentary, and shared learning. Another perspective is that when targeting revision in this way, investment in non-essential additional reading is innately low. Learners in this exercise tailor their revision specifically to pass an assessment, and not explicitly to further their understanding beyond the module learning outcomes. It is of note that questionnaire comments allude to these resources as beneficial for future learning.

This explorative study was of small scale, in that it involved only one fourth-year cohort of pharmacy students in one UK school. Despite several reminders, the response rate of $28 \%$ was low, and it needs to be acknowledged that the views of those who did not respond may differ. This is a limitation with this study. Nevertheless, this study does offer valuable perceptions. Further research should take account of moderator time in creating and particularly maintaining the page. Valuable insights could also be gained from investigating more objective measures of impact, such as comparing data on examination scores and grades to previous and future cohorts. Student satisfaction could also be explored in relation to social media and the potential correlation of social media with wider student/staff engagement.

Health professionals employ social networks for legitimate professional purposes (especially Twitter and LinkedIn). 6,7,37,38 It would be advantageous to consider bridging the link between undergraduate student and postgraduate professional by developing the authentic use of social media in undergraduate studies. Widespread use of social media throughout an undergraduate program, linked to established platforms used by practicing pharmacists, could provide this. This could reinforce the savvy and appropriate use of social media for professional purposes, as graduates step into the workplace, a health care system in which social media is gaining prominence.

\section{Conclusion}

This exploratory study shows that pharmacy students will actively collaborate in social media to prepare themselves for written assessments. This evaluation shows that Facebook can be productive in self- and peer learning at the undergraduate level. Indeed students are willing to support each other's learning using Facebook and feel more supported for assessment by their tutor, through online socialization. Since VLE platforms appear less successful at achieving student engagement, pharmacy educators should develop social learning into curricula design by considering social media. This would be timely when considering the use of social media by patients, and health care organizations connecting with patients through virtual platforms. ${ }^{38}$ Learners may better understand their future practice if given the opportunity to learn using social media. Further research is needed to explore if this approach affects examination performance and indeed extends into practice.

\section{Conflict of Interests}

None.

\section{References}

1. Office of National Statistics. Social Networking: UK as a Leader in Europe; 2014. Available at: 〈https://newsroom.fb. com/company-info/. Accessed August 2, 2015〉. 
2. Facebook. Newsroom. Available at: 〈http://www.ons.gov.uk/ ons/rel/rdit2/internet-access-households-and-individuals/ social-networking-the-uk-as-a-leader-in-europe/sty-social-net working-2012.html ; 2014 Accessed August 2, 2015.

3. Cartledge P, Miller M, Phillips B. The use of social-networking sites in medical education. Med Teach. 2013;35(10):847-857.

4. Mazman SG, Usluel YK. Modeling educational usage of Facebook. Comput Educ. 2010;55(2):444-453.

5. Deng L, Tavares NJ. From Moodle to Facebook: exploring students' motivation and experiences in online communities. Comput Educ. 2013;68:167-176. http://dx.doi.org/10.1016/j. chb.2015.02.042.

6. Benetoli A, Chen TF, Aslani P. The use of social media in pharmacy practice and education. Res Soc Adm Pharm. 2015;11(1):1-46.

7. Hawn C. Report from the field: take two aspirin and tweet me in the morning: how twitter, facebook, and other social media are reshaping health care. Health Aff. 2009;28(2):361-368.

8. Royal Pharmaceutical Society. Social media guidance for pharmacists. Available at: 〈http://www.rpharms.com/unsecuresupport-resources/social-media-guidance.asp $\rangle ; 2014$ Accessed August 2, 2015.

9. Vrocharidou A, Efthymiou I. Computer mediated communication for social and academic purposes: profiles of use and University students' gratifications. Comput Educ. 2012;58(1): 609-616.

10. White J, Kirwan P, Lai K, Walton J, Ross S. Have you seen what is on Facebook? The use of social networking software by healthcare professions students. Br Med J Open. 2013;3(7):A.

11. Hall M, Hanna LA, Huey G. Use and views on social networking sites of pharmacy students in the United Kingdom. Am J Pharm Educ. 2013;77(1):Article 9.

12. Junco R. The relationship between frequency of Facebook use, participation in Facebook activities, and student engagement. Comput Educ. 2012;58(1):162-171.

13. Dyson B, Vickers K, Turtle J, Cowan S, Tassone A. Evaluating the use of Facebook to increase student engagement and understanding in lecture-based classes. Higher Educ. 2014; http://dx.doi.org/10.1007/s10734-014-9776-3 [in press].

14. Estus EL. Using facebook within a geriatric pharmacotherapy course. Am J Pharm Educ. 2010;74(8): Article 10.

15. Fox BI, Varadarajan R. Use of twitter to encourage interaction in a multi-campus pharmacy management course. Am J Pharm Educ. 2011;75(5): Article 86.

16. Tower M, Latimer S, Hewitt J. Social networking as a learning tool: Nursing students' perception of efficacy. Nurse Educ Today. 2014;34(6):1012-1017.

17. Fenwick T. Social media and medical professionalism: rethinking the debate and the way forward. Acad Med. 2014;89(10): 1331-1334.

18. Ness GL, Sheehan AH, Snyder ME, Jordan J, Cunningham JE, Gettig JP. Graduating pharmacy students' perspectives on e-professionalism and social media. Am J Pharm Educ. 2013; 77(1): Article 146.
19. Cain J, Romanelli F. E-professionalism: a new paradigm for a digital age. Curr Pharm Teach Learn. 2009;1(2):66-70.

20. Kaczmarczyk JM, Chuang A, Dugoff L, et al. e-Professionalism: a new Frontier in medical education. Teach Learn Med. 2013;25(2):165-170.

21. Osman A, Wardle A, Caesar R. Online professionalism and Facebook-falling through the generation gap. Med Teach. 2012;34(8):e549-e556.

22. Cain J, Scott DR, Akers P. Pharmacy students' facebook activity and opinions regarding accountability and e-professionalism. Am J Pharm Educ. 2009;73(6): Article 104.

23. Wenger E. Communities of Practice and Social Learning Systems. Organization. 2000;7(2):225-246.

24. Wenger E. Communities of Practice: Learning, Meaning and Identity. 1st ed, Cambridge: Cambridge University Press; 1998.

25. Divall MV, Kirwin JL. Using facebook to facilitate courserelated discussion between students and faculty members. Am J Pharm Educ. 2012;76(2):Article 32.

26. Pensky M. Teaching Digital Natives: Partnering for Real Learning. 1st ed, London: Sage Publications; 2010.

27. Arteaga Sanchez R, Cortijo V, Javed U. Students' perceptions of Facebook for academic purposes. Comput Educ. 2014;70: 138-149. http://dx.doi.org/10.1016/j.compedu.2013.08.012.

28. Schafheutle EI, Hassell K, Ashcroft DM, Hall J, Harrison S. How do pharmacy students learn professionalism. Int J Pharm Pract. 2012;20(2):118-128.

29. Hanning L, Price G, Scanlan J, et al. A new approach to clinical pharmacy practice teaching in the four-year degree course. Pharm J. 2002;269(7209):163-165.

30. Maloney S, Moss A, Ilic D. Social media in health professional education: a student perspective on user levels and prospective applications. Adv Health Sci Educ. 2014;9(5):687-697.

31. Salmon GK. E-moderation: The Key to Teaching and Learning Online. 2nd ed, London, New York: Routledge Falmer; 2004.

32. Attride-Stirling J. Thematic networks: an analytic tool for qualitative research. Qual Res. 2001;1(3):385-405.

33. Maloney E. What Web 2.0 can teach us about learning. Chronicle Higher Educ. 2007;53(18):B26.

34. Cain J, Policastri A. Using Facebook as an informal learning environment. Am J Pharm Educ. 2011;75(1): Article 207.

35. Prescott J, Wilson S, Becket G. Pharmacy students want guidelines on Facebook and online professionalism. Pharm J. 2012;289(7717):163-164.

36. Kear K, Chetwynd F, Jefferis H. Social presence in online learning communities: the role of personal profiles. Res Learn Technol. 2014;22:A. Article 19710. http://dx.doi.org/10.3402/ rlt.v22.19710.

37. Antheunis ML, Tates K, Nieboer TE. Patients' and health professionals' use of social media in health care: motives, barriers and expectations. Patient Educ Couns. 2013;92(3): 426-431.

38. Bell M, Douglas J, Cutts C. How pharmacy's adoption of social media can enhance patient outcomes. Integr Pharm Res Pract. 2014;3:39-47. http://dx.doi.org/10.2147/IPRP.S42774. 